3 Chandrasekharan NV, Dai H, Roos KL, Evanson NK, Tomsik J, Elton TS, et al. COX-3, a cyclooxygenase-1 variant inhibited by acetaminophen and other analgesic/antipyretic drugs: cloning, structure, and expression. Proc Nat Acad Sci USA 2002:99:13926-31.

4 Schwab JM, Schluesener HJ, Laufer S. COX-3: just another COX or the solitary elusive target of paracetamol? Lancet 2003;361:981-2.

5 Stevenson DD, Simon RA. Lack of cross-reactivity between rofecoxib and aspirin in aspirin-sensitive patients with asthma. J Allergy Clin Immunol 2001;108:47-51

6 Kwoh CK, Feinstein AR. Rates of sensitivity reactions to aspirin: problems in interpreting the data. Clin Pharmacol Ther 1986:40:494-505.

7 Levy S, Volans G. The use of analgesics in patients with asthma. Drug Safety 2001;24:829-41.
8 Vally H, Taylor ML, Thompson PJ. The prevalence of aspirin intolerant asthma (AIA) in Australian asthmatic patients. Thorax 2002;57:569-74.

9 Nizankowska E, Bestynska-Krypel A, Cmiel A, Szczeklik A. Oral and bronchial provocation tests with aspirin for diagnosis of aspirin-induced asthma. Eur Respir J 2000:15:863-9.

10 Szczeklik A, Sanak M. Molecular mechanisms in aspirin-induced asthma. Allergy Clin Immunol Int 2000;12:171-6.

11 Szczeklik A, Nizankowska E, Duplaga M. Natural history of aspirininduced asthma. Eur Respir J 2000;16:432-6.

12 Settipane RA, Schrank PJ, Simon RA, Mathison DA, Christiansen SC, Stevenson DD. Prevalence of cross-sensitivity with acetaminophen in aspirin-sensitive asthmatic subjects. J Allergy Clin Immunol 1995;96:480-5. (Accepted 14 November 2003)

\title{
Training for patients in a randomised controlled trial of self management of warfarin treatment
}

\author{
Ellen Murray, David Fitzmaurice, Debbie McCahon, Chris Fuller, Hardeep Sandhur
}

Self management of warfarin treatment by patients, using a point of care coagulometer for testing international normalised ratios, is comparable to home glucose monitoring and may provide a robust model of service provision. ${ }^{12}$ Self management can lead to improvements in patients' self efficacy, closer adherence to treatment, and increased control of treatment with oral anticoagulants. ${ }^{3}$

We report data on the effectiveness of the training programme used for a clinical trial (self management of anticoagulation: a randomised trial, SMART) which aimed to evaluate clinical and cost effectiveness of self management compared with routine care. UK guidelines indicated that training to a standard acceptable is essential, although the nature of the training was not clearly defined. ${ }^{2}$

\section{Participants, methods, and results}

Patients aged over 18 with a long term indication for warfarin, from 48 general practices in the West Midlands, were eligible. After giving consent patients were randomly allocated to either self management or routine care. Data on demographics, age, ethnic origin, condition requiring warfarin treatment, and education were collected at consent. Nurses experienced in anticoagulation management, who had attended a course organised by the researchers to ensure standards and consistency, provided training. Patients randomised to self management attended at least two training sessions. Sessions were adapted from a German national programme, ${ }^{4}$ were practice based, and were held one week apart. The aims of training were to ensure that patients had a theoretical understanding of oral anticoagulation and INR monitoring, that they (or their carers) were able to measure the INR reliably by using a point of care system (Coaguchek S, Roche Diagnostics), and that they were able to interpret the INR in terms of appropriate warfarin dose. We assessed patients individually for competence in undertaking self management in terms of accurately performing an INR test (by using the point of care system), quality control issues, dosing algorithm and adjustment of dosage, and documenting INR results and adverse events. Capable patients were given equipment for home testing, otherwise an additional session was arranged, and if they were still not considered capable of self management they were returned to usual care.

Of 2586 patients invited to participate 608 (24\%) provided written consent, with central telephone randomisation to self management $(\mathrm{n}=327)$ and usual care $(n=281)$. Of the patients randomised to self management 85/327 (26\%) did not complete training (table). We defined reasons for dropout during training as either self exclusion of patients themselves or exclusion by the researcher. Of the patients $67 / 85(79 \%)$ excluded themselves. The primary reason was manual difficulty with the procedure. Altogether 54/67 (81\%) patients were generally unhappy with the procedure, and of those $30 / 54(56 \%)$ gave the reason as trouble in obtaining sufficient capillary blood and placing the sample on to the test strip. In total 242/327 (74\%) of patients passed the training assessment and started self management, and of those $212(88 \%)$ completed 12 months of self management.

The participants who completed training were significantly younger than the group that did not complete training (61 $v 71$ years, $\mathrm{P}=0001$ ). Significantly more patients were educated to GCSE or above standard among the patients who completed training $(\mathrm{P}=0.003)$.

\section{Comment}

Although we used a training programme to train 242 unselected patients successfully in self management of warfarin treatment, $76 \%(1978 / 2586)$ of patients

Details of patients enrolled in a randomised controlled trial of self management of warfarin treatment

\begin{tabular}{lccc} 
& No of patients & $\begin{array}{c}\text { Mean age } \\
\text { (years) }\end{array}$ & $\begin{array}{c}\text { Educated to } \\
\text { GCSE or above }\end{array}$ \\
\hline Patients invited & 2586 & 69 & - \\
\hline Patients recruited & $618(24 \%)$ & 65.2 & - \\
\hline Patients randomised to self management & 327 & 64.1 & - \\
\hline Control & 281 & 66.4 & - \\
\hline $\begin{array}{l}\text { Patients randomised to self management who } \\
\text { completed training }\end{array}$ & $242(74 \%)$ & 61.2 & $120(50 \%)$ \\
$\begin{array}{l}\text { Patients randomised to self management who } \\
\text { did not complete training }\end{array}$ & $85(26 \%)$ & 71.4 & $30(32 \%)$ \\
\hline
\end{tabular}

Department of Primary Care and General Practice, Medical School, University of Birmingham, Birmingham B15 2TT

Ellen Murray $M R C$ research fellow David Fitzmaurice professor of primary care research Debbie McCahon research associate Chris Fuller research associate Hardeep Sandhur research fellow, data management

Correspondence to: E Murray

e.t.murray@

bham.ac.uk

BMJ 2004;328:437-8 
invited chose not to undertake self management and may therefore not consider this a desirable option. To our knowledge this is the first UK trial that invited unselected patients to self manage warfarin and as such may give a real indication of expected uptake. For patients keen to undertake self management three quarters were able to complete training. These patients considered it a convenient and valuable method of controlling their own health and most were enthusiastic to continue after the trial. If self management by patients is to become established standardisation and dissemination of training are needed, accompanied by practical guidelines to encourage back up from clinicians.

Contributors: EM managed the study, drafted the paper, and is a lead investigator. DF is principal investigator and critically revised the paper. DMcC and $\mathrm{CF}$ were research associates involved in field work, training, and assessing patients' data collection and management, and both reviewed the paper. HS pro- duced the databases supported data cleaning and analysis and reviewed the paper. EM and DF are the guarantors.

Funding: Medical Research Council.

Competing interests: EM and DF have been reimbursed by Roche Diagnostics for attending several conference and to support educational programmes within the University of Birmingham's Department of Primary Care.

Ethical approval: Midland Research Ethics Committee.

1 Fitzmaurice DA, Murray ET, Gee KM, Allan TF, Hobbs FDR. A randomised controlled trial of patient self-management of oral anticoagulation treatment compared with primary care management. J Clin Pathol 2002:55:845-9.

2 Fitzmaurice DA, Machin SJ. Recommendations for patients undertaking self management of oral anticoagulation. BMJ 2001;323:985-9.

3 Sawicki PT. A structured teaching and self-management program for patients receiving oral anticoagulation. A randomized controlled trial. JAMA 1999;281:145-50.

4 Morsdorf S, Erdlenbruch W, Taborski U, Schenk JF, Erdlenbruch K, Novotny-Reichert G, et al. Training of patients for self management of oral anticoagulant therapy: standards, patient suitability and clinical aspects. Semin Thromb Hemost 1999;25:109-15. (Accepted 10 October 2003)

\title{
Coeliac disease and schizophrenia: population based case control study with linkage of Danish national registers
}

\author{
William W Eaton, Preben Bo Mortensen, Esben Agerbo, Majella Byrne, Ole Mors, Henrik Ewald
}

Department of

Mental Health,

Bloomberg School

of Public Health,

Johns Hopkins

University, 624

North Broadway,

Baltimore, MD

21205, USA

William Eaton

professor

National Centre for

Register-Based

University,

Taasingegade 1 ,

8000 Aarhus C,

Denmark

Preben Bo

Mortensen

professor

Esben Agerbo

assistant professor

Majella Byrne

assistant professor

continued over

BMJ 2004;328:438-9
Research, Aarhus

Dohan proposed that an inherited defect interacting with an environmental trigger of gluten precipitated schizophrenia in some individuals, and provided supportive epidemiological evidence. ${ }^{1}$ Some clinical trials and case studies showed that a cereal free diet improved remission of symptoms of schizophrenia. ${ }^{2}$ The most important genetic marker found in the study of coeliac disease $(6 \mathrm{p} 23-\mathrm{p} 22.3)^{3}$ is very close to the dysbindin locus, which has been implicated in schizophrenia. ${ }^{4}$

\section{Participants, methods, and results}

The case sample comprised 7997 people older than 15 who were admitted to a Danish psychiatric facility for the first time between 1981 and 1998 with a diagnosis of schizophrenia and known maternal identity. For each case we randomly selected 25 controls from a subsample of all available controls, matched by year of birth and sex.

We searched records of the national patients' register for a history of autoimmune diseases in cases, controls, and their parents, in a manner that protected the anonymity of the participants. Denmark has few private health facilities, and treatment is free of charge, so that coverage of visits is nearly $100 \%$ complete. Diagnoses were according to the International Classification of Diseases (8th revision, 1981-94; 10th revision,

Relative risk of schizophrenia for people with autoimmune intestinal diseases

\begin{tabular}{lccccc} 
Autoimmune diseases & \multicolumn{2}{c}{ Prevalence per $\mathbf{1 0 0 0}$} & & \multicolumn{2}{c}{ Relative risk } \\
\cline { 2 - 3 } \cline { 5 - 6 } in cases or parents & Cases (7997) & Controls $\mathbf{( 1 9 9}$ 915) & & Univariate & Adjusted ${ }^{*} \mathbf{~ ( 9 5 \% ~} \mathbf{~ C l )}$ \\
\hline Coeliac disease & 1.5 & 0.5 & & 3.2 & $3.2(1.8-5.9)$ \\
\hline Crohn's disease & 4.5 & 3.4 & & 1.3 & $1.4(1.0-1.9)$ \\
\hline Ulcerative colitis & 6.2 & 4.7 & & 1.3 & $1.4(1.0-1.8)$ \\
\hline
\end{tabular}

*Adjusted for wealth quarter of parents, urban residence, and family history of schizophrenia.
1995-8). We included coeliac disease (and closely related dermatitis herpetiformis), on the basis of prior scientific literature, and two autoimmune gastrointestinal conditions (ulcerative colitis and Crohn's disease), for which little or no scientific literature exists that implies an association with schizophrenia. We included major risk factors for schizophrenia because these might be confounders of an association with coeliac disease: socioeconomic position, urban residence, and family history of schizophrenia. ${ }^{5}$ Four patients, five mothers of patients, and three fathers of patients were being treated for coeliac disease before the patient entered a psychiatric facility (1.5 per 1000 population, table). In a conditional logistic regression model the relation of risk factors for schizophrenia replicated that found in the literature. ${ }^{5}$ The univariate relative risk for schizophrenia, given coeliac disease, was 3.2 $(\mathrm{P}<0.0001)$, unchanged by addition of the covariates (table). The adjusted relative risks for Crohn's disease and ulcerative colitis, when using the covariates discussed above, were both $1.4(\mathrm{P}<0.08$ for Crohn's disease, and $\mathrm{P}<0.03$ for ulcerative colitis). When coeliac disease and four additional cases of dermatitis herpetiformis were combined in an adjusted model as described above, the relative incidence for either of the two disorders compared with neither disorder was 3.1 (95\% confidence interval 1.8 to 5.2 ).

\section{Comment}

A history of coeliac disease is a risk factor for schizophrenia, as shown in this epidemiological study. The risk relation is strong but reflects a small proportion of cases of either disorder, since both disorders are rare. 